\title{
Integrated ZVT Cell Applied to Decentralized Multi-String PV System
}

\author{
R. C. Beltrame ${ }^{1}$, M. I. Desconzi ${ }^{1}$, M. L. S. Martins ${ }^{2}$, J. R. Pinheiro ${ }^{1}$ and H. L. Hey ${ }^{1}$ \\ ${ }^{1}$ Power Electronics and Control Research Group, Federal University of Santa Maria \\ 97105-900, Santa Maria, RS, BRAZIL \\ Phone number: +55 55 32208463, e-mail: beltrame@mail.ufsm.br \\ ${ }^{2}$ Power Analysis and Processing Research Group, Federal University of Technology - Parana \\ 85503-390, Pato Branco, PR, BRAZIL \\ Phone number: +55 46 32202572, e-mail: mlucio@utfpr.edu.br
}

\begin{abstract}
This paper exploits the advantages of using a cascaded connection of dc-dc step-up stages for a series string of photovoltaic (PV) panels in a single-phase residential/commercial grid connected installation. It is demonstrated that when multistring PV systems are adopted in order to minimize shadowing problems, it is required to employ some approach to reduce the switching losses (turn-on losses of MOSFETs and mainly diode reverse-recovery losses) of the dc-dc step-up stages. As a multistring PV system is normally comprised by several dc-dc stepup stages, integrated soft-switching topologies are attractive due to their compactness, reliability and low cost. Thus, this work proposes to use an integrated zero-voltage transition (ZVT) cell, which assists all dc-dc step-up stages and employs a very compact circuit, enabling to minimize the switching losses, improving the system efficiency. The proposed cell makes use of a magnetically-coupled auxiliary voltage source implemented by adding a secondary winding on the input inductors. In order to validate the proposed topology, experimental results are presented.
\end{abstract}

\section{Key words}

Multi-string photovoltaic (PV) system, dc-dc step-up converter, zero-voltage switching (ZVS), zero-voltagetransition (ZVT).

\section{Introduction}

Nowadays, there has been a significant growth of the photovoltaic (PV) market mostly due to the proliferation of grid connected PV systems [1]. Likewise other intermittent renewable sources, to optimize the PV array area and make the implantation of grid connected PV systems economically viable, it is essential to drain the maximum power produced by the PV panels, which is accomplished by means of a maximum power point (MPP) track algorithm [2]-[3] commonly applied to the front-end dc-dc stage.

Due to dissimilarities of panel production, different temperatures and irradiations - due to panel orientation, aging or partial shading [4] - PV modules cannot produce identical energy in an array. Hence, in a long string PV array, this situation may result in the lost of the MPP, which reduces the overall efficiency of the entire array and, in some cases, can cause degeneration of the panels due to the hot spot phenomenon. To ensure the maximum production of electricity even when shading or other dissimilarities are present, decentralized PV systems have been proposed in the literature. Some works demonstrate that a gain of up to $16 \%$ of generated energy could be achieved with decentralized PV systems [5].
In general, decentralized PV systems split the maximum power point tracker (MPPT) stage, which can be dedicated exclusively to a single or a small group of PV panels. Decentralized systems can be grouped in three different approaches, namely module integrated systems [6], string and multi-string systems [7].

As a multi-string PV system is comprised by several dcdc step-up stages, to reduce the turn-on losses of MOSFETs and diode reverse-recovery losses of all dc-dc stage is a quite complex task since the auxiliary circuitry may increase significantly the converter size, weight and cost. Additionally, a large semiconductor count could reduce the reliability of the PV system.

This way, this paper exploits the advantages of using a cascaded connection of dc-dc step-up stages for a series string of PV panels in a single-phase residential/commercial grid connected installation with an integrated soft-switching topology [8]. It is proposed the use of a very compact integrated zero-voltage-transition (ZVT) circuit, which assists all the dc-dc step-up stages, enabling to minimize both the turn-on losses of MOSFETs and diode reverse-recovery losses.

\section{Performance of Multi-String MPPT Stages}

Multi-string PV systems combine the use of individual MPPT algorithm with the lower costs of a central inverter PV system [9], reducing the possibility of shadowing mismatches.

Fig. 1 (a) shows the efficiency comparison of multi-string PV systems with one through four input dc-dc step-up stages. The analyzed system makes use of the Hypothetical Standard Module (HSM) specified in Table I. The step-up stage parameters and components are defined in Table II.

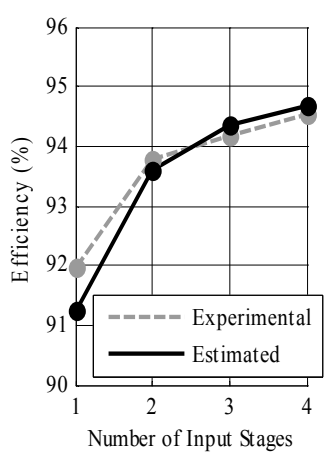

(a)

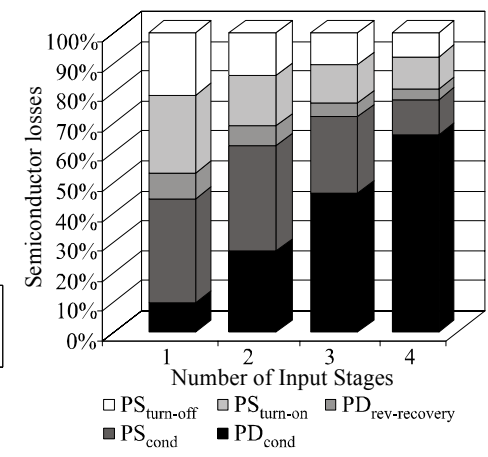

(b)
Fig. 1. Decentralized multi-string dc-dc step-up stage performance. (a) Efficiency of hard switched system. (b) Semiconductor power loss balance. 
Table I - Parameters for the Simulated Hypothetical Standard Module

\begin{tabular}{|l|c|}
\hline \multicolumn{1}{|c|}{ PARAMETER } & VALUE \\
\hline $\begin{array}{l}\text { Open circuit voltage, } V_{O C} \\
\left.\text { (short circuit current, } I_{S C}\right)\end{array}$ & $21.9 \mathrm{~V}(8.02 \mathrm{~A})$ \\
\hline Peak power voltage (current) & $17.6 \mathrm{~V}(7.39 \mathrm{~A})$ \\
\hline $\begin{array}{l}\text { Panel peak power } \\
\text { (number of panels of the array) }\end{array}$ & $130 \mathrm{~W}(3)$ \\
\hline
\end{tabular}

Table II - Simulated Input dc-dc Step-up Stage Parameters.

\begin{tabular}{|l|l|}
\hline \multicolumn{1}{|c|}{ PARAMETER } & \multicolumn{1}{c|}{ VALUE } \\
\hline Switching frequency, $f_{s}$ & $100 \mathrm{kHz}$ \\
\hline Input filter inductor, $L(N$ of turns $)$ & $285 \mu \mathrm{H}(22$ turns $)$ \\
\hline Ferrite core & $\mathrm{NEE}-65 / 26$ \\
\hline Maximum flux density, $B_{\operatorname{Max}}$ & $0.2 \mathrm{~T}$ \\
\hline Copper wire & $3 \times 63 \times 37$ AWG (Litz) \\
\hline Output capacitor, $C_{o}$ & $470 \mu \mathrm{F}$ \\
\hline Main switch (MOSFET) / Diode & IRFP460 / 8ETH06 \\
\hline
\end{tabular}

It can be seen in Fig. 1 (a) that the efficiency is proportional to the number of input stages. It occurs because the larger the number of stages is, the lower the input dc-dc converter gain is for the same dc bus voltage (defined as $250 \mathrm{~V}$ ), reducing the RMS current through the transistor and the related conduction losses. Additionally, the switching losses (turn-on losses of MOSFET and diode reverse-recovery losses) are also minimized because the voltage applied on semiconductor devices is reduced.

The distribution of the losses for each dc-dc step-up stage is presented in Fig. 1 (b). It can be concluded that switching losses in both diode and MOSFET are reduced as the output voltage of the dc-dc converters is reduced. Thus, two dc-dc step-up stages are the critical situation for single-phase PV systems, were a $400-450 \mathrm{~V}$ bus voltage is required for the $220 \mathrm{~V}_{\text {rms }}$ standard inverter stage. It can be seen for the two MPPT case that both transistor turn-on and turn-off losses represents about $23 \%$ of the semiconductor losses, and the diode switching losses represents about $35 \%$, confirming the importance of reducing the switching losses.

\section{Proposed Integrated ZVT Cell}

According to Section II, large reverse-recovery currents of the diodes affect the system efficiency. To overcome this problem, passive [10] and active approaches [11]-[12] have been proposed for the dc-dc step-up converter. Zero-voltage mode techniques, such as the ZVT, are especially suitable to overcome the aforementioned drawback because it reduces the diode reverse-recovery losses by controlling the $d i / d t$ slope of the current during the turn-off of the diode. Furthermore, it effectively minimizes the switching losses and also promotes the absorption of the parasitic capacitances energy of semiconductor devices [13], minimizing the turn-on capacitive losses when majority carrier devices such as MOSFETs are employed.

Fig. 2 (a) shows a generic diagram of a decentralized multi-string PV system employing ZVT cells. It can be seen that any dc-dc step-up stage presents an individual ZVT cell. There are several ways to implement the ZVT auxiliary commutation circuit (ACC), depending on how the auxiliary voltage source (AVS) of the ACC is synthesized [11]. Nevertheless, in its simplest way, the

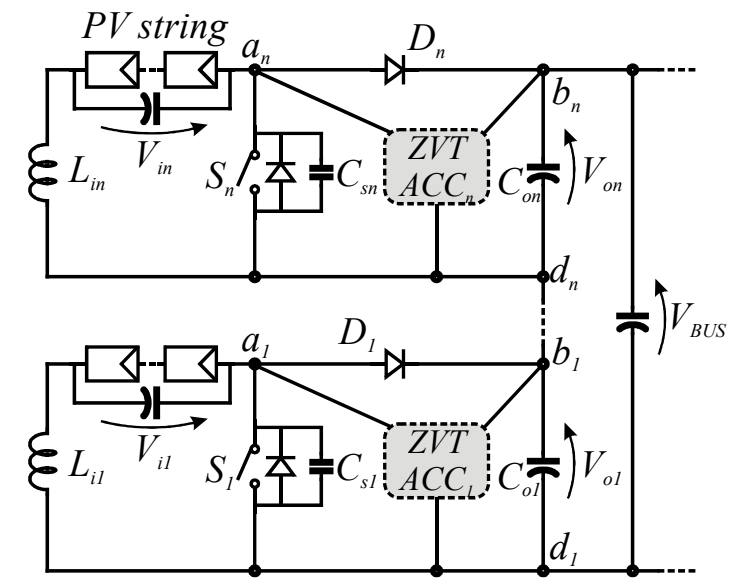

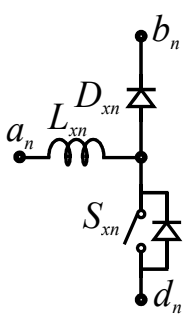

(b)

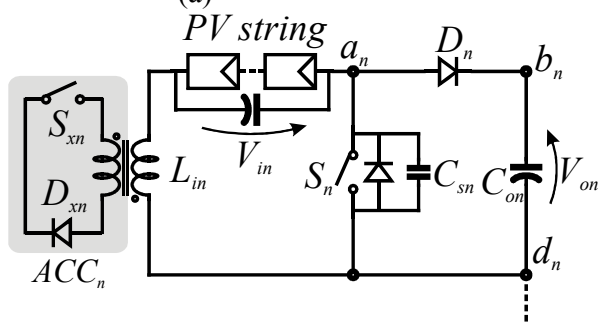

(c)
Fig. 2. Decentralized multi-string ZVT systems. (a) Generic circuit diagram. (b) Simple auxiliary circuit.

(c) Magnetic-coupled ACC.

AVS is comprised by an inductor and a pole composed by a switch and a diode, as depicted in Fig. 2 (b). In converters that present a filter inductor, as the dc-dc stepup converter, an AVS implemented by a magneticcoupling with the filter inductor, as proposed by [14], is advantageous because the voltage source is implemented in the same magnetic core of the filter inductor, and the auxiliary inductor can be implemented by means of the leakage inductance [15]. This way, these features result in a very compact topology in that there are no extra magnetic components, as presented in Fig. 2 (c).

\section{A. The Integration Concept}

In order to reduce the ACC component count in decentralized PV multi-string systems, a new integrated ZVT cell is proposed, as shown in Fig. 3, which employs a very compact circuit that can assist all dc-dc step-up stages, as shown in Fig. 3 (a). The proposed integrated ZVT cell can also assist other topologies, such as the dcdc step-up/down stages presented in Fig. 3 (b). The proposed ACC makes use of a magnetically-coupled AVS implemented by adding a secondary winding on the input inductors. The ZVT cell presented in Fig. 3 makes possible to minimize the diode reverse-recovery losses of $D_{I}$ to $D_{n}$ by controlling the $d i / d t$ slope of their currents, and to assist the turn-on of $S_{1}$ to $S_{n}$ simply by using a phase difference of $360^{\circ} / n$ among their command signals, where $n$ is the number of dc-dc step-up stages, or by synchronizing their turn-on commutations.

\section{B. Integrated ZVT Cell Operation}

For simplicity, it is considered only one dc-dc step-up converter, as presented in Fig. 4, where the coupledinductor was replaced by its cantilever model [15]. Furthermore, the input inductor $\left(L_{l}\right)$ was approximated by 


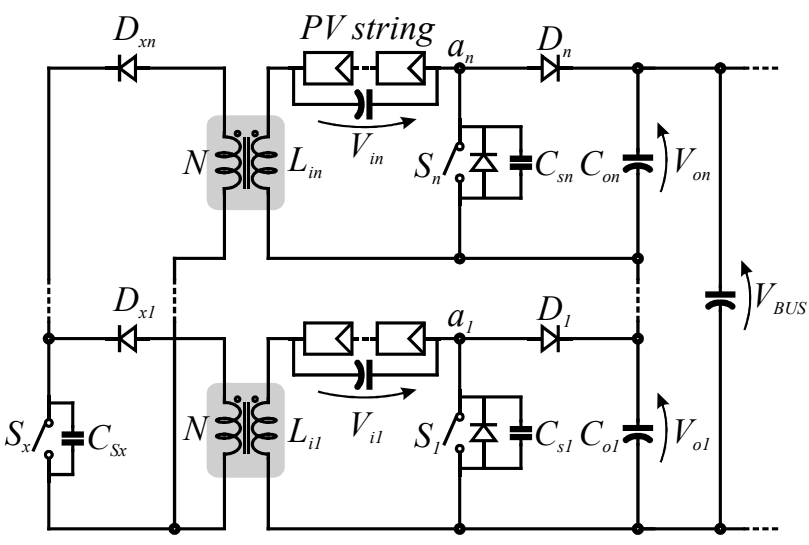

(a)

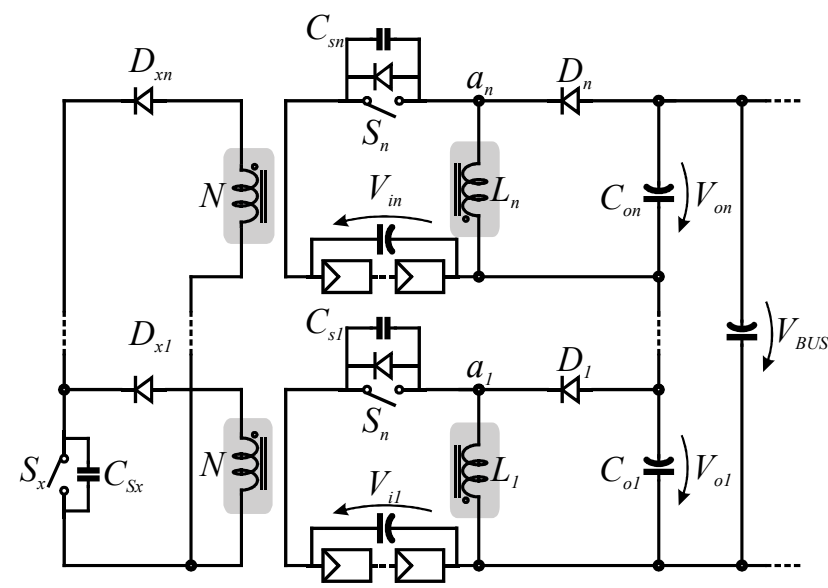

(b)

Fig. 3. Proposed multi-string PV system with integrated ZVT cell. (a) Decentralized with step-up MPPT stages (boost converters).

(b) Decentralized with step-up/down MPPT stages (buck-boost converters).

a constant current source $\left(I_{L 1}\right)$ during the switching period. This approximation can be made if the magnetizing inductance of the coupled-inductor $\left(L_{m}\right)$ is much larger than the leakage inductance $\left(L_{x}\right)$ and the ripple of the current through $L$ in a switching period is small.

Mode $1\left(t \leq t_{0}\right)$ : previous to the ACC operation, $S_{l}$ is turned off and $D_{l}$ is conducting $I_{L l}$, as presented in Fig. 4 (a) and in Fig. 5 for $t \leq t_{0}$. During this mode, the voltage on $C_{S I}\left(v_{S I}\right)$ and the current through $L_{x}\left(i_{L x}\right)$ are $V_{o l}$ and zero, respectively.

Mode $2\left(t_{0}<t \leq t_{1}\right)$ : aiming to commutate $I_{L l}$ from $D_{l}$ to $S_{l}$, the auxiliary switch $S_{x}$ is turned on at " $t_{0}$." The circuit configuration during this mode is represented in Fig. 4 (b) and the main theoretical waveforms in Fig. 5 for $t_{0}<t \leq t_{1}$. The voltage on $C_{s l}$ is $V_{o l}$ and the current through $L_{x}$ increases linearly with a slope given by $N\left(V_{o 1}-V_{i 1}\right) / L_{x}$. It is important to notice that the turns ratio $(N)$ must be positive in order to apply a positive voltage on $L_{x}$. This mode ends at " $t_{l}$," when $N i_{L x}(t)$ reaches $I_{L l}$ and $D_{l}$ turns off with a controlled di/dt slope. The time duration of this mode, defined as $\Delta t_{1}=t_{1}-t_{0}$, can be calculated by (1).

$$
\Delta t_{1}=\frac{L_{x} I_{L 1}}{N^{2}\left(V_{o 1}-V_{i 1}\right)}
$$

Mode $3\left(t_{1}<t \leq t_{2}\right)$ : this mode begins at " $t_{1}$," when $D_{l}$ turns off, and both $C_{s l}$ and $L_{x}$ go to a resonant process. The circuit configuration during this mode is represented in Fig. 4 (c) and the main theoretical waveforms in Fig. 5 for $t_{1}<t \leq t_{2}$. The voltage on $C_{s 1}$ goes zero during the resonant process. The current peak through $L_{x}$ can be calculated by (2)-(3).

$$
\begin{gathered}
i_{L x(\max )}=\frac{V_{o 1}-V_{i 1}}{Z}+\frac{I_{L 1}}{N} \\
Z=\sqrt{L_{x} / C_{s 1}}
\end{gathered}
$$

In order to achieve the zero-voltage-switching (ZVS) condition to $S_{l}$, it is mandatory that $v_{S I}(t)$ reduces to zero volt. It can be demonstrated that the restriction (4) must be observed in order to satisfy the aforementioned ZVS condition. The restriction (4) implies that the converter gain must be always higher than two.

$$
\frac{V_{o 1}}{V_{i 1}} \geq 2
$$

This mode ends at " $t_{2}$," when $v_{S I}(t)$ reduces to zero and is clamped by the antiparallel diode of $S_{1}$. Thus, the time duration of this stage, defined as $\Delta t_{2}=t_{2}-t_{1}$, can be calculated by (5)-(6).

$$
\begin{gathered}
\Delta t_{2}=\frac{1}{\omega_{n}} \arccos \left(\frac{V_{i 1}}{V_{i 1}-V_{o 1}}\right) \\
\omega_{n}=\frac{N}{\sqrt{L_{x} C_{s 1}}}
\end{gathered}
$$

Mode $4\left(t_{2}<t \leq t_{3}\right)$ : after $v_{S I}(t)$ reaching zero at " $t_{2}$," the antiparallel diode of $S_{I}$ stars conducting, as presented in Fig. 4 (d). The voltage on $C_{s l}$ remains clamped at zero volt and the current through $L_{x}$ decreases linearly with a slope given by $-N V_{i 1} / L_{x}$. It is important to notice that $N$ must be positive in order to apply a negative voltage over $L_{x}$. The main theoretical waveforms are presented in Fig. 5 for $t_{2}<t \leq t_{3}$. This mode ends at " $t_{3}$ ", when $N i_{L x}(t)$ reduces under $I_{L 1}$ and $S_{I}$ starts assuming gradually $I_{L l}$. The time duration of this mode, defined as $\Delta t_{3}=t_{3}-t_{2}$, can be calculated by (7)-(8). $S_{1}$ must be turned on under ZVS during this mode.

$$
\begin{gathered}
\Delta t_{3}=\frac{L_{x}\left(N i_{L x}\left(t_{2}\right)-I_{L 1}\right)}{N^{2} V_{i 1}} \\
i_{L x}\left(t_{2}\right)=\frac{V_{o 1}-V_{i 1}}{Z} \sin \left(\omega_{n} \Delta t_{2}\right)+\frac{I_{L 1}}{N}
\end{gathered}
$$

Mode $5\left(t_{3}<t \leq t_{4}\right)$ : at " $t_{3}$," when $S_{1}$ starts assuming gradually $I_{L l}$, the circuit goes to the configuration represented in Fig. 4 (e). The circuit operation is similar to that in the previous mode. The main theoretical waveforms are presented in Fig. 5 for $t_{3}<t \leq t_{4}$. This mode ends at " $t_{4}$," when $i_{L x}(t)$ reduces to zero and $D_{x I}$ turns off under a controlled $d i / d t$ slope. It is important to highlight that after the turn-off of $D_{x l}, S_{x}$ can be turned off under zero-current switching (ZCS). Thus, an IGBT can be employed as auxiliary switch. The time duration of this mode, defined as $\Delta t_{4}=t_{4}-t_{3}$, can be calculated by (9). 


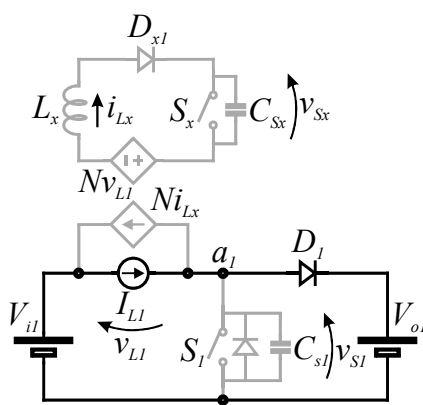

(a) Mode $1\left(t \leq t_{0}\right)$.

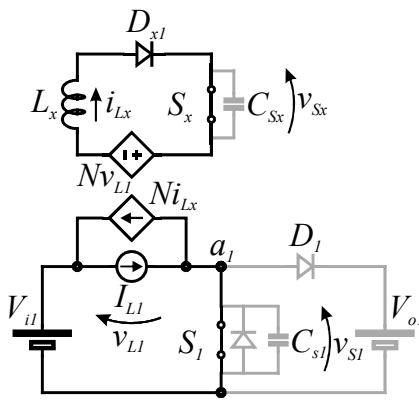

(e) Mode $5\left(t_{3}<t \leq t_{4}\right)$.

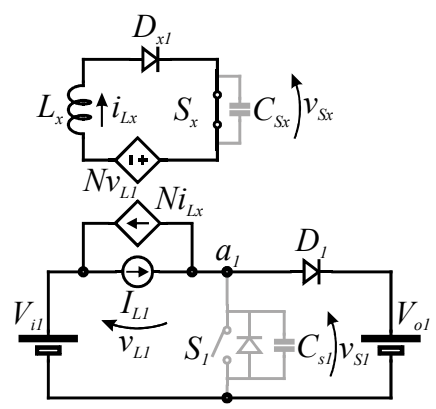

(b) Mode $2\left(t_{0}<t \leq t_{1}\right)$.

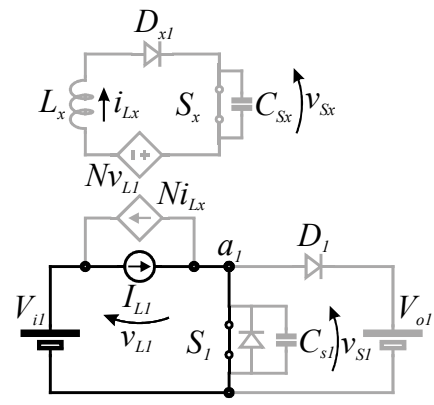

(f) Mode $6\left(t_{4}<t \leq t_{5}\right)$.

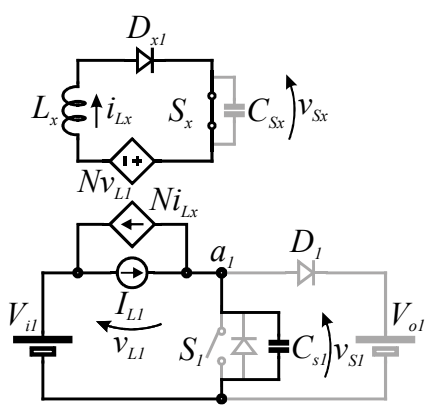

(c) Mode $3\left(t_{1}<t \leq t_{2}\right)$.

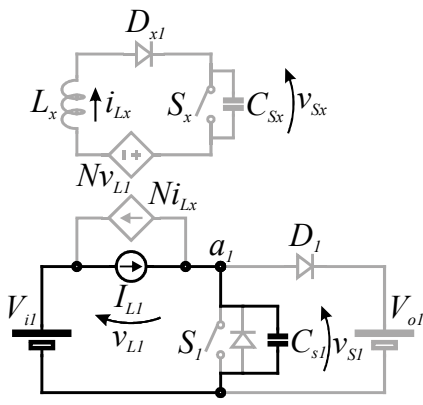

(g) Mode $7\left(t_{5}<t \leq t_{6}\right)$.

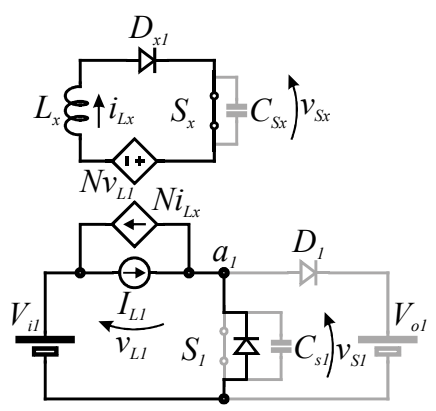

(d) Mode $4\left(t_{2}<t \leq t_{3}\right)$.

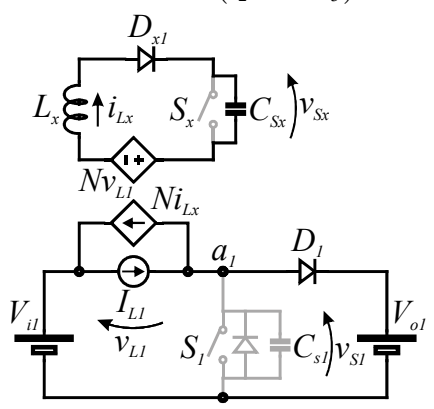

(h) Mode $8\left(t_{6}<t \leq t_{7}\right)$.

Fig. 4. Operation modes of a single dc-dc step-up stage with the proposed integrated ZVT cell.

$$
\Delta t_{4}=\frac{L_{x} I_{L 1}}{N^{2} V_{i 1}}
$$

Mode $6\left(t_{4}<t \leq t_{5}\right)$ : after $D_{x l}$ turning off at " $t_{4}$," $S_{1}$ conducts $I_{L I}$. Thus, $v_{S I}(t)$ and $i_{L x}(t)$ are both zero. During this mode, represented in Fig. 4 (f), the pulse-width modulation $(\mathrm{PWM})$ is implemented. This mode ends at " $t_{5}$," when $S_{1}$ is turned off. The main theoretical waveforms are presented in Fig. 5 for $t_{4}<t \leq t_{5}$.

Mode $7\left(t_{5}<t \leq t_{6}\right)$ : this mode begins at " $t_{5}$ " "when $S_{1}$ is turned off and $I_{L I}$ is transferred to the snubber capacitor $C_{s l}$. This way, $C_{s l}$ is charged linearly with a slope given by $I_{L 1} / C_{s 1}$. The circuit configuration during this mode is represented in Fig. $4(\mathrm{~g})$ and the main theoretical waveforms are presented in Fig. 5 for $t_{5}<t \leq t_{6}$. This stage ends at " $t_{6}$," when $v_{S 1}(t)=V_{o 1}$ and $D_{I}$ starts conducting $I_{L l}$, clamping $v_{S I}(t)$ at $V_{o I}$. Additionally, the time duration of this mode, defined as $\Delta t_{5}=t_{6}-t_{5}$, can be calculated by (10).

$$
\Delta t_{5}=\frac{C_{s 1} V_{o 1}}{I_{L 1}}
$$

Mode $8\left(t_{6}<t \leq t_{7}\right)$ : this mode only exists due to the intrinsic capacitance of $S_{x}\left(C_{S x}\right)$. In the following analysis, it is assumed that the linear charge of $C_{s l}$ (snubber commutation) was finished. Thus, the voltage applied over $L_{l}$ is $V_{i 1}-V_{o 1}$ at " $t_{6}$." This voltage, reflected to the ACC side, turns $D_{x I}$ on and enables $L_{x}$ and $C_{S x}$ to start a resonant process. The circuit configuration during this mode is represented in Fig. $4(\mathrm{~h})$ and the main theoretical waveforms in Fig. 5 for $t_{6}<t \leq t_{7}$. This mode ends at " $t_{7}$," when $i_{L x}(t)$ reduces to zero and $D_{x l}$ is turned off. This way, the circuit returns to the configuration of Fig. 4 (a) (mode 1). The voltage over $S_{x}$ at " $t_{7}$ ” presents the level defined in (11).

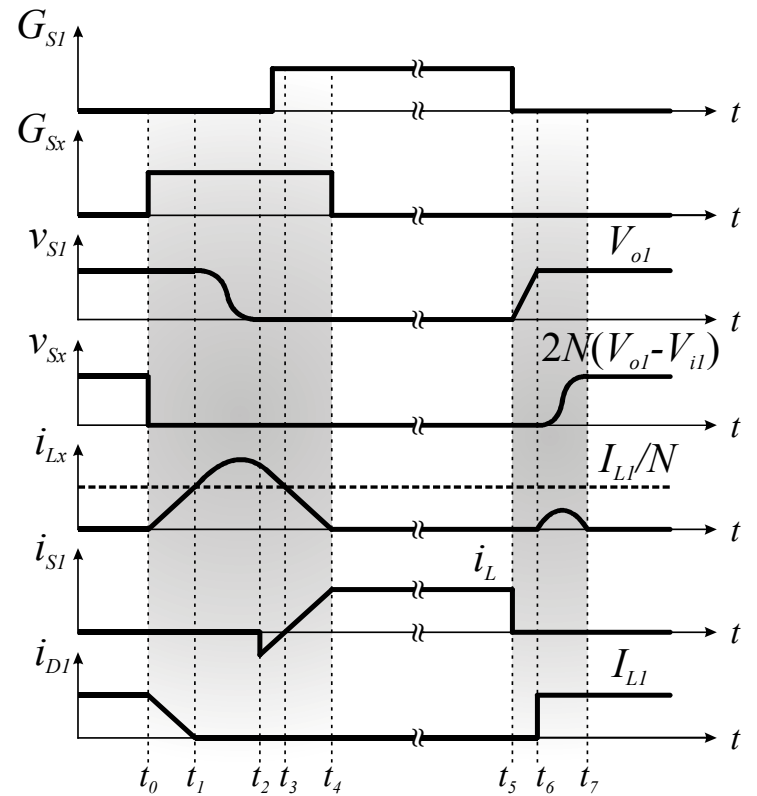

Fig. 5. Theoretical waveforms of the proposed ZVT topology.

$$
v_{S x}\left(t_{7}\right) \leq 2 N\left(V_{o 1}-V_{i 1}\right)
$$

\section{Design Methodology}

The design methodology for the proposed ZVT circuit is based on the selection of $L_{x}$ and $N$ in order to satisfy the restrictions that guarantee the proper ACC operation and also limit the voltage and current stresses in the semiconductor devices of the dc-dc step-up stages. The detailed project methodology is presented in [16]. Applying this methodology, the auxiliary circuit parameters have been chosen as $L_{x}=7.1 \mu \mathrm{H}$ and $N=1.21$ in order to satisfy the restrictions defined in Table III. 
Table III - Converter Specification and Semiconductor Limitations

\begin{tabular}{|l|l|}
\hline \multicolumn{1}{|c|}{ PARAMETER } & \multicolumn{1}{|c|}{ VALUE } \\
\hline Input power $\left(P_{i n}\right)$ & $390 \mathrm{~W}$ \\
\hline Switching frequency $\left(f_{s}\right)$ & $100 \mathrm{kHz}$ \\
\hline Input voltage $\left(V_{i l}\right) /$ Output voltage $\left(V_{o l}\right)$ & $52.8 \mathrm{~V} / 250 \mathrm{~V}$ \\
\hline Max. voltage over $S_{x}\left(v_{S x(\max )}\right) / D_{x}\left(v_{D x(\max }\right)$ & $480 \mathrm{~V} / 480 \mathrm{~V}$ \\
\hline Max. current through the ACC $\left(i_{A C C(\max )}\right)$ & $13 \mathrm{~A}$ \\
\hline Max. $d i / d t$ of $D\left(d i / d t_{D}\right)$ and $D_{x I}\left(d i / d t_{D x}\right)$ & $100 \mathrm{~A} / \mu \mathrm{s}$ \\
\hline Snubber capacitor $\left(C_{S I}\right)$ & $480 \mathrm{pF}\left(C_{O S S}\right)$ \\
\hline
\end{tabular}

\section{Experimental Results}

In order to verify the effectiveness of the proposed topology, an experimental analysis is carried out for a single dc-dc step-up converter employing the integrated ZVT cell presented in Fig. 3 (a). The semiconductors employed in the prototype are summarized in Table IV, as well as some additional ACC specifications.

For this analysis the PV panels were emulated by a constant voltage source with a voltage level equal to the MPP voltage, and the MPP current was drained from the voltage source by adjusting the duty-cycle of the dc-dc step-up converter.

Fig. 6 presents the experimental waveforms of the converter operating at nominal power. In Fig. 6 (a)-(b) are presented the stead-state waveforms of the command signals of both main $\left(v_{G S I}(t)\right)$ and auxiliary switches $\left(v_{G S x}(t)\right)$, as well as their voltage $\left(v_{S I}(t)\right.$ and $v_{S x}(t)$, respectively), and the current through the auxiliary inductor $\left(i_{L x}(t)\right)$. It is possible to see in Fig. 6 (a)-(b) that the ACC intervention demands a small portion of the switching period (due to a project restriction [16]). It must

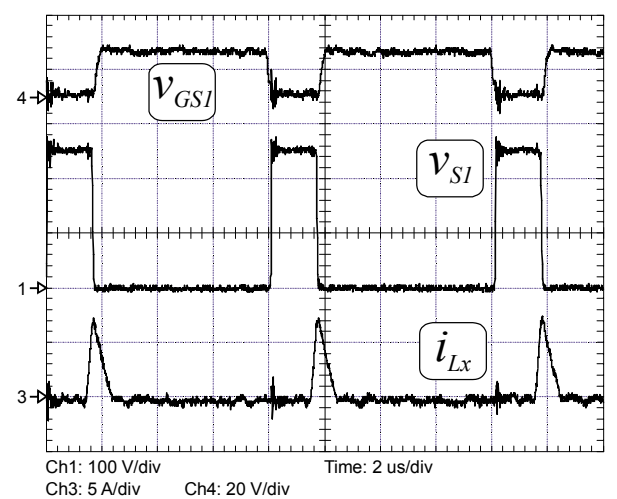

(a)

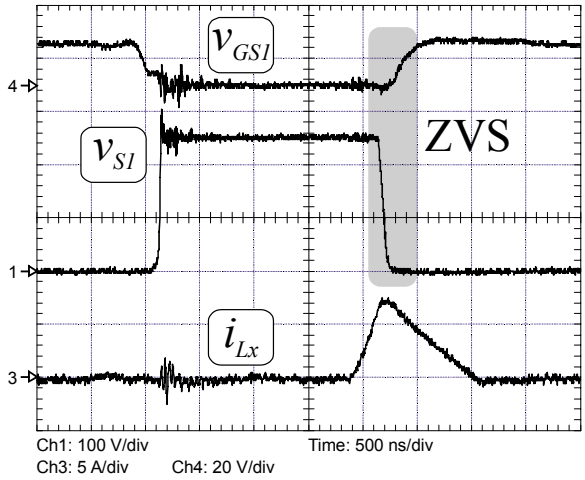

(c)
Table IV - Semiconductor Devices and ACC Specifications

\begin{tabular}{|l|l|l|}
\hline \multicolumn{1}{|c|}{ PARAMETER } & \multicolumn{1}{|c|}{ VALUE } & \multicolumn{1}{c|}{ NOTE } \\
\hline Main switch $\left(S_{l}\right)$ & IRFP460 & Discrete MOSFET \\
\hline Main diode $\left(D_{l}\right)$ & $8 \mathrm{ETH} 06$ & Discrete Diode \\
\hline Aux. switch $\left(S_{x}\right)$ & IRG4BC20UD & Discrete IGBT \\
\hline Aux. diode $\left(D_{x l}\right)$ & $8 \mathrm{ETH} 06$ & Discrete Diode \\
\hline Ferrite core & NEE $-65 / 26$ & - \\
\hline Cooper Wire & $3 \times 63 \times 37 \mathrm{AWG}$ & Litz \\
\hline Input inductor $\left(L_{l}\right)$ & $285 \mu \mathrm{H}$ & - \\
\hline Aux. inductor $\left(L_{x}\right)$ & $7.1 \mu \mathrm{H}$ & Leakage \\
\hline Turns ratio $(N)$ & 1.21 & $\begin{array}{l}N(\mathrm{pri})=22 \times 3 \\
N(\mathrm{sec})=27 \times 1\end{array}$ \\
\hline
\end{tabular}

be noted that the linear rising of $i_{L x}(\mathrm{t})$ (with $d i / d t$ controlled by $L_{x}$ ) corresponds to a linear falling of the current through $D_{l}$, reducing its reverse-recovery losses. It is possible to see in Fig. 6 (b) that $S_{x l}$ is turned off after $i_{L x}(t)$ reaching zero, characterizing a ZCS commutation.

Furthermore, Fig. 6 (c) presents the details of the turn-on commutation of $S_{l}$. As can be seen in Fig. 6 (c), the main switch $S_{l}$ is turned on only after $v_{s l}(t)$ reaching zero, characterizing a ZVS commutation. For a comparison purpose, Fig. 6 (d) presents the turn-on commutation of $S_{1}$ without the ACC assistance.

Fig. 7 shows the measured efficiency of the dc-dc step-up prototype evaluated experimentally as a function of PV module power for a set of irradiances defined a priori. It can be observed that the efficiencies are inversely proportional to the PV module power, since the conduction losses increase with the module current. In spite of it, the integrated ZVT dc-dc prototype presented higher efficiency for the entire range of powers.

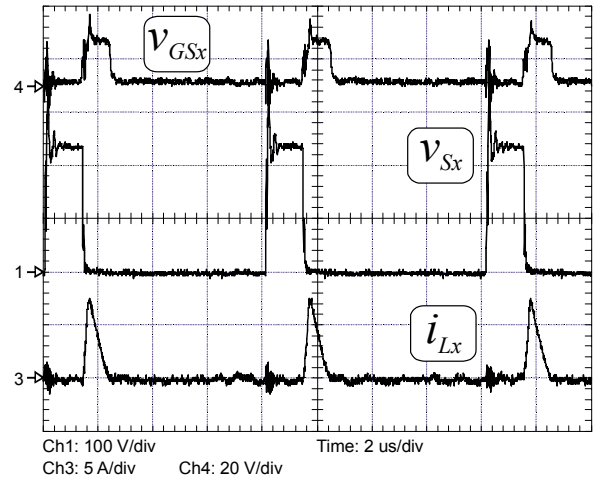

(b)

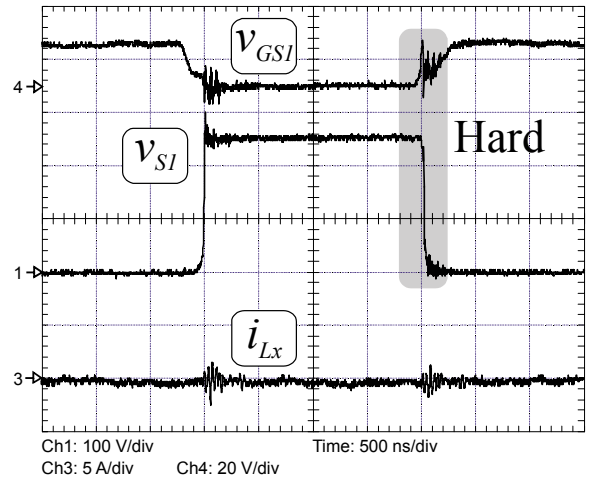

(d)

Fig. 6. Experimental results. (a) Main circuit in stead-state operation. (b) Auxiliary commutation circuit in stead-state operation. Comparison between the (c) ZVS and (d) Hard-switched commutations. 


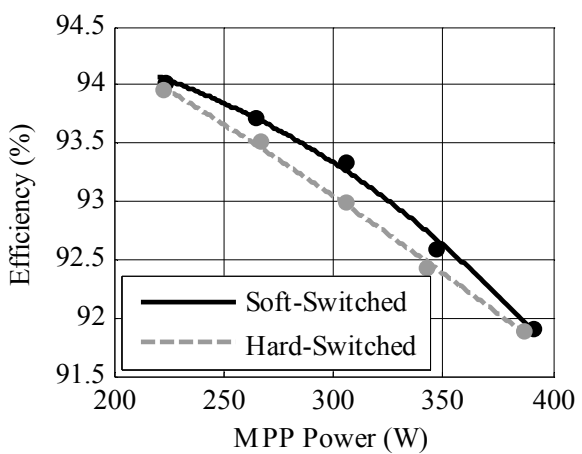

Fig. 7. Converter efficiency in function of solar irradiation in a range from 600 to $1000 \mathrm{~W} / \mathrm{m}^{2}$ (powers from 222 to $390 \mathrm{~W}$ ).

\section{Conclusion}

This paper presented and analyzed an integrated ZVT cell that makes use of a magnetically-coupled AVS implemented simply by adding a secondary winding on the input inductors of the dc-dc step-up stages. The proposed ACC assists all the dc-dc step-up converters of a decentralized multi-string PV system employing a very compact circuit, reducing the cost and size of the overall system, and improving its performance by reducing the turn-on capacitive losses of the main switches and the diode reverserecovery losses. Thus, the benefits of using multi-string PV systems, such as reducing the possibility of shadowing mismatches and increasing the generated energy are kept without penalizing the system reliability and cost.

The proposed integrated ZVT topology was analyzed theoretically and experimentally. The proposed topology was validated by experimental results obtained from a single dc-dc step-up converter operating at $390 \mathrm{~W}$ and $100 \mathrm{kHz}$. The experimental results proved the effectiveness of the converter.

\section{Acknowledgement}

The authors would like to express their gratitude to "Coordenação de Aperfeiçoamento de Pessoal de Nível Superior - CAPES" and "Conselho Nacional de Desenvolvimento Científico e Tecnológico - CNPQ" (proc. $\mathrm{n}^{\mathrm{o}} 307798 / 2009-7$ and proc. $\mathrm{n}^{\circ} 478154 / 2009-7$ ) for financial support.

\section{References}

[1] K. Cory, J. Coughlin, T. Jenkin, J. Pater, and B. Swezey, "Innovations in wind and solar PV financing," Technical Report NREL/TP-670-42919, 2008.
[2] N. Femia, G. Petrone, G. Spagnuolo, and M. Vitelli, "Optimization of perturb and observe maximum power point tracking method," IEEE Trans. on Power Electronics, Vol. 20, No. 4, pp. 963-973, July 2005.

[3] G.J. Yu, Y.S. Jung, J.Y. Choi, I. Choy, J.H. Song, and G.S. Kim, "A novel two-mode MPPT control algorithm based on comparative study of existing algorithms," in Proc. Photovoltaic Specialists Conf., 2002, pp. 1531-1534.

[4] G. Carannante, C. Fraddanno, M. Pagano, and L. Piegari, "Experimental performance of MPPT algorithm for photovoltaic sources subject to inhomogeneous insolation," IEEE Trans. on Industrial Electronics, Vol. 56, No. 11, pp. 4374-4380, 2009.

[5] J. Imhoff, J.R. Pinheiro, J.L. Russi, D. Brum, R. Gules, and H.L. Hey, "Dc-dc converters in a multi-string configuration for stand-alone photovoltaic systems," in Proc. IEEE Power Electronics Specialists Conf., 2008, pp. 2806-2812.

[6] M. Meinhardt, T. O’Donnell, H. Schneider, J. Flannery, C.O. Mathuna, P. Zacharias, and T. Krieger, "Miniaturised 'low profile' module integrated converter for photovoltaic applications with integrated magnetic components," in Proc. IEEE Applied Power Electron. Conf. and Exposition, Vol. 1, 1999, pp. 305-311.

[7] M. Meinhardt, D. Wimmer, and G. Cramer, "Multi-stringconverter: the next step in evolution of string-converter," in Proc. IEEE Europen Conf. on Power Electronics and Applications, 2001.

[8] L. Schuch, C. Rech, J.R. Pinheiro, "Integrated auxiliary commutation circuits: a generalised approach," Power Electronics, IET, Vol. 2, pp. 42-51, 2009.

[9] J.M.A. Myrzik, and M. Calais, "String and module integrated inverters for single-phase grid connected photovoltaic systems - a review," in Proc. IEEE Power Tech Conf., Vol. 2, 2003.

[10] R.T.H. Li, H.S.H. Chung, and A.K.T. Sung, "Passive lossless snubber with minimum voltage and current stress for boost PFC," in Proc. IEEE Energy Conversion Congress and Exposition, 2009, pp. 940-947.

[11] M.L.S. Martins, J.L. Russi, and H.L. Hey, "Zero-voltage transition PWM converters: a classification methodology," in Proc. IEE Electric Power Applications, Vol. 152, No. 2, pp. 323-334, 2005.

[12] C.M. Wang, "A novel zero-voltage-switching PWM boost rectifier with high power factor and low conduction losses," IEEE Trans. Industrial Electronics, Vol. 52, No. 2, pp. 427435, Apr. 2005.

[13] M.L.S. Martins and H.L. Hey, "Self-commutated auxiliary circuit ZVT PWM converters," IEEE Trans. on Power Electronics, Vol. 19, No. 6, pp. 1435-1445, Nov. 2004.

[14] J.P. Gegner and C.Q. Lee, "Zero-voltage-transition converters using a simple magnetic feedback technique," in Proc. IEEE Power Electronics Specialists Conf., 1994, Vol. 1, pp.590-596.

[15] J.L. Russi, M.L.S. Martins, and H.L. Hey, "Coupledfilter-inductor soft-switching techniques: principles and topologies," IEEE Trans. on Industrial Electronics, Vol. 55, No. 9, pp. 3361-3373, Sept. 2008.

[16] R.C. Beltrame, M.I. Desconzi, H.T. Camara, M.L.S Martins, H.L. Hey, "Decentralized multi string PV system with integrated ZVT cell," in Proc. Congresso Brasileiro de Automática, 2010, pp. 3729-3736. 